\title{
Peach Rusty Spot Epidemics: Management with Fungicide, Effect on Fruit Growth, and the Incidence-Lesion Density Relationship
}

\author{
Laura A. Furman and Norman Lalancette, Rutgers University, Agricultural Research and Extension Center, \\ Bridgeton, NJ 08302-5919; and James F. White, Jr., Rutgers University, Cook College, Department of Plant Biol- \\ ogy and Pathology, New Brunswick, NJ 08901-8520
}

\begin{abstract}
Furman, L. A., Lalancette, N., and White, J. F., Jr. 2003. Peach rusty spot epidemics: Management with fungicide, effect on fruit growth, and the incidence-lesion density relationship. Plant Dis. 87:1477-1486.

Different numbers of consecutive fungicide applications, beginning at petal fall and continuing into the summer, were examined for their effect on rusty spot epidemics. Disease progressions for each fungicide level were quantified by fitting either the logistic or monomolecular model. When the weighted absolute infection rate $(\rho)$ and maximum disease level $\left(K_{\max }\right)$ parameters were expressed as functions of the number of applications, the logistic decline model provided the best fit for five of six data sets. This model described a gradual decrease in $\rho$ and $K_{\max }$ in response to the initial fungicide application, a rapid decline in parameter values with the addition of one or two applications, and a diminished parameter response as fungicide applications continued toward the end of the epidemic. Based on examination of model behavior across all 3 years of the study, adequate management was achieved with a total of three to five fungicide applications. Additional analyses of area under the disease progress curve and final disease intensity at harvest supported these results and indicated that further reduction in fungicide usage may be possible. Unlike earlier findings, rusty spot did not significantly decrease fruit volume or weight at midseason or at harvest; as lesion density increased, fruit volume remained constant. The relationship between disease incidence and lesion density within any given year was best explained by the zero-intercept version of the exponential model. However, comparison of model parameters across years revealed significant seasonal variation. Nevertheless, the incidence-lesion density relationships were fairly uniform across years at incidence values below 0.5 , where lesion density increased gradually and in a near-linear fashion.
\end{abstract}

Additional keywords: Podosphaera leucotricha, powdery mildew, Prunus persica

Rusty spot of peach (Prunus persica L. Batsch) is believed to be caused by the apple powdery mildew fungus Podosphaera leucotricha (Ellis \& Everh.) E. S. Salmon $(14,18)$. The pathogen does not grow or sporulate well on peach $(1,2,11,21)$, and few etiological studies have been conducted to confirm its identity; thus, other causal agents may exist. Fruit infection results in the development of orange to brown lesions that can cover large areas of the surface. As the lesions age, necrosis and lignification of the epidermal cells and loss of the trichomes result in the infected areas becoming smooth and russeted $(1,21)$. In New Jersey, incidence of fruit infection on unprotected susceptible cultivars often approaches $100 \%$. Commercial crop loss has been

Corresponding author: N. Lalancette

E-mail: lalancette@aesop.rutgers.edu

This research was funded in part by the New Jersey Agricultural Experiment Station.

Accepted for publication 26 July 2003.

Publication no. D-2003-1010-01R

(C) 2003 The American Phytopathological Society estimated as high as $\$ 504 /$ ha when environmental conditions are favorable for disease development (16).

Current disease management recommendations specify that fungicide protection should begin at the shuck split stage of fruit growth, the time at which the calyx separates from the young fruit, and continue on an 8- to 10-day schedule (11). Termination of the susceptible period was unknown; therefore, many New Jersey growers continued fungicide applications throughout the summer, and often until harvest. This schedule can result in as many as nine consecutive applications for late-maturing cultivars. However, a recent temporal analysis indicated that epidemics began at shuck split, but terminated at initiation of pit-hardening, approximately 2 months prior to harvest (10). Thus, the main objective of this study was to determine the number of fungicide applications needed during this period for optimum management of rusty spot epidemics. In epidemiological terms, this optimal level is attained when the epidemic rate is suppressed to a low level, but not necessarily to zero $(6,7)$. That is, the additional gain in crop value from producing a disease-free crop is insignifi- cant relative to the economic and environmental costs.

The application of fungicide decreases effectiveness of inoculum, resulting in a reduction of the rate of the epidemic $(22,26)$. Although this process has been well documented for many pathosystems (6), little information is available on the quantitative nature of the relationship. Thus, a second objective of our study was to model the rate of rusty spot epidemics as a function of the number of fungicide applications. Similarly, because a rate reduction results in a lowering of the maximum disease level, the relationship between this latter epidemic parameter and number of fungicide applications also was modeled. Quantitative descriptions of these relationships would provide a better understanding of how successive fungicide applications influence disease progress. Preliminary results of this study have been presented (8).

The above model-based approach focuses on the effect of fungicide applications on the disease increase or progressive phase of the epidemic that occurs early in the growing season. However, peach rusty spot epidemics also exhibit an atypical degressive phase during the 20- to 30-day period prior to harvest (10). Although the exact cause of this decline in visually detectable lesions is currently unknown, its occurrence can impact the amount of disease control needed for management. Thus, in addition to examination of epidemic parameters during the progressive phase, the area under the disease progress curve (progressive + degressive phases) and final disease intensity at harvest also were analyzed to provide alternative approaches for evaluating fungicide control. If the lateseason disease decline has a differential effect on the treatments applied during the progressive phase of the epidemic, then we would expect the model-based approach to predict a different number of fungicide applications than the area and final disease approaches.

Yield losses due to peach rusty spot result from a reduction in fruit quality, thereby lowering the grade of the fruit or making it unmarketable. However, large fruit are generally more valuable than small fruit $(16,24)$; therefore, another potential economic loss is a reduction in fruit size. A prior study showed that rusty spot caused a significant reduction in the weight 
of fruit by midseason (18). However, peach fruit increase in size both early and late in the growing season (24) and no data were collected after the second growth phase in this earlier study. Thus, a third objective of our research was to determine if fruit at harvest also exhibited a reduction in size as a result of rusty spot infection.

The various treatments in this study produced a wide range of disease levels, thereby providing an opportunity to explore the relationship between disease incidence and lesion density. Of these two measures of disease intensity, lesion density is preferred because it relates directly to the severity of disease or amount of fruit surface infected. However, disease incidence is much more rapidly and accurately assessed. Thus, the fourth and final objective of this study was to determine the quantitative relationship between these two disease measures for predictive purposes.

\section{MATERIALS AND METHODS}

Orchard site. The peach orchard chosen for experimentation consisted of the susceptible cv. Jerseyqueen grafted on 'Lovell' rootstock. Results from past studies indicated that this orchard had a history of high rusty spot incidence. The orchard was planted in a narrow rectangular design with four rows of 67 trees each. Rows were spaced at $7.6 \mathrm{~m}$ and trees were planted at 5.5-m intervals. Approximately $25 \%$ of the 21-year-old trees were missing throughout the orchard; thus, about 200 trees were available for experimentation.

Experimental design. In each year of the study, treatments consisted of increasing numbers of consecutive fungicide applications that began in spring and ended in midsummer. Trees in the first treatment received no fungicide; the second treatment consisted of a single spray at petal fall; the third treatment had applications at petal fall and early shuck-split; the fourth treatment had sprays at petal fall, shucksplit, and first cover; and so on for the remaining treatments. Thus, the independent variable was the number of sequential fungicide applications.

In 1999, 2000, and 2001, treatments ranged from zero through eight, seven, and five fungicide applications covering the period from petal fall through sixth, fifth, and third cover, respectively. Petal fall sprays were applied when the majority $(>95 \%)$ of the flower petals had abscised. Shuck-split sprays were applied 8 days later, which corresponded to less than $10 \%$ of the fruit having a split calyx. First cover sprays were performed 10 days after shuck-split sprays, at which time the majority $(>95 \%)$ of calyxes had fallen off, exposing the entire fruit surface. Subsequent fruit cover sprays were applied at 12to 20-day intervals. Fungicides were applied between 26 April and 21 July on days 116, 124, 134, 146, 160, 175, 188, and 202 in 1999; from 20 April to 17 July on days
$111,119,129,142,157,172$, and 185 in 2000; and from 30 April to 20 July on days 120, 128, 138, 151, and 171 in 2001. The effect of a single fungicide application at full bloom, on day 110, also was examined in 2001 .

Treatments were replicated five times in a randomized complete block design. Blocks were arranged perpendicular to the length of the orchard, each one being four rows wide by approximately 13 trees long. Plots consisted of single trees surrounded on all sides by nonsprayed buffer trees. All treatment applications consisted of the fungicide myclobutanil (Nova 40W; Dow AgroSciences, Indianapolis, IN) applied at a rate of $140.1 \mathrm{~g}$ a.i./ha. Applications were made at volume, 935 liters/ha; tractor speed, $3.4 \mathrm{~km} / \mathrm{h}$; and pressure, $690 \mathrm{kPa}$. Fungicides were applied with a commercial Durand-Wayland AF32-100 airblast sprayer with an 81-cm fan in 1999 and a research Rears Pak-Blast-Plot airblast sprayer with a 71-cm fan in 2000 and 2001.

Disease assessments. Tree plots were chosen each April and the same trees were sampled throughout that growing season. At each assessment, a total of 40 fruit were arbitrarily picked from each plot in each replicate block; previous research verified use of destructive sampling for monitoring peach rusty spot epidemics (10). The total number of rusty spot lesions was recorded for each sampled peach. Disease incidence was calculated as the proportion of infected fruit, and lesion density as the average number of lesions per fruit.

Disease assessments began in May each year and ended in late August for the 1999 and 2000 seasons; in 2001, assessments ended in late June. In all, 15 assessments were made weekly in 1999 . However, in 2000, the assessments were performed twice weekly early in the season and once every 2 weeks from mid to late season, for a total of 13 assessments. Similarly, in 2001, 9 of the 10 assessments were made twice weekly and the last was taken 2 weeks later.

Fruit size was assessed by recording the weight and estimating the volume of 20 fruit arbitrarily selected from the 40 harvested fruit. Measurements of fruit length $(L)$, width parallel to the suture $\left(W_{1}\right)$, and width perpendicular to the suture $\left(W_{2}\right)$ were recorded. Volume $(V)$ of each peach was calculated using the formula for an ellipsoid, where $V=4 / 3 \pi(L / 2)\left(W_{1} / 2\right)\left(W_{2} / 2\right)$. In 1999 and 2000, fruit volume was assessed twice at midseason, between days 162 and 187, and once at harvest on days 238 and 223, respectively. Fruit weights also were recorded on the same days in 2000. Fruit volume and weight were recorded in 2001 only during the midseason period, at days 176 and 190. The midseason assessments were conducted at approximately 12 to 40 days after initiation of endocarp sclerification (pit hardening).
Management with fungicide. The model-based approach, used for assessing fungicide effects on the epidemic parameters, required the execution of several interrelated steps. First, the logistic or monomolecular models were fit to the early-season progressive phase of the epidemics (10). Maximum disease incidence did not approach 1.0 for any of the epidemics; therefore, nonlinear regression analysis (NLIN procedure, Statistical Analysis System v. 8.0; SAS Institute, Cary, NC) was used to avoid underestimation of the epidemic rate $(r)$ and allow inference of the upper asymptote maximum disease incidence $\left(K_{\max }\right)(15)$. Separate models were fit to the disease progression data for treatments zero through five in 1999 and 2001 and zero through six in 2000. That is, models were fit only to those treatments that were completed during the progressive phase of the epidemic. All analyses were performed on the means of the five replicates.

The second step of this approach was to determine the mathematical relationship between the number of fungicide applications $(\mathrm{N})$ and the two dependent variables, $r$ and $K_{\max }$. To allow direct comparison of the rate parameter curves for different disease progress models, the estimated rates first were standardized to the weighted absolute infection rate, rho $(\rho)$, using the formula

$\rho=r\left[K_{\max } /(2 m+2)\right]$

where $m=0$ or 2 for monomolecular and logistic rates, respectively (3). Next, two different models that characterize nonlinear, negative slopes were examined for their fit to the $\rho$ and $K_{\max }$ data. The first model, a version of the negative exponential function, was defined as

$\left(\rho, K_{\max }\right)=a+b \exp (-c \mathrm{~N})$

where parameters $a, b$, and $c$ represent the minimum, maximum $-a$, and rate, respectively. The second model, a version of the logistic that also describes decline, was defined as

$\left(\rho, K_{\max }\right)=a+b /[1+\exp (c(\mathrm{~N}-d))]$

where parameters $a, b, c$, and $d$ define the minimum, maximum - $a$, shape, and inflection point on the abscissa, respectively. All models were fit using nonlinear regression analysis (NLIN procedure, SAS v. 8.0). Model fits in both the first and second steps were evaluated by examining significance of the $F$ value, relative variation $(\mathrm{RV})$ of parameter estimates $(\mathrm{RV}=$ standard error/parameter estimate), plots of residuals, and graphs of predicted versus observed data.

Determination of the minimum number of fungicide applications that provided adequate disease control was performed by examining graphs of the appropriate, fitted models. The optimum value of $\mathrm{N}$ was achieved when the rate of change of either 
$\rho$ or $K_{\max }$ approached zero; that is, the tangent to the predicted curve had a slope near zero. A zero slope was neither necessary nor desirable because further increases in $\mathrm{N}$ provided minimal benefit in reducing either $\rho$ or $K_{\max }$ (diminishing returns).

The second approach for examining fungicide effects on disease development involved comparison of treatments using a standard analysis of variance (ANOVA; GLM procedure, SAS v. 8.0). Two different types of response variables were examined: areas under the disease incidence (AUDIC) and lesion density (AULDC) curves and final disease incidence and lesion density at harvest. Area calculations were based on observations from epidemic onset in May to time of harvest in August. Final disease data were observed just prior to harvest on days 238 (26 August) and 223 (10 August) in 1999 and 2000, respectively. Separate analyses were performed for 1999 and 2000; no analysis was performed for 2001 because assessments in that year were conducted only during the early progressive phase of the epidemic. Treatment levels were compared using the Waller-Duncan $k$-ratio $t$ test $(P \leq$ $0.05 ; k=100)$.

Effect of disease on fruit growth. Three analyses were conducted to determine if rusty spot severity affected growth of the fruit. The first analysis, performed on data from nonsprayed trees, compared fruit volumes and weights of healthy versus diseased fruit at midseason and at harvest. Separate analyses of variance were performed for each independent variable in each year of the study (GLM procedure, SAS v. 8.0). The second analysis determined if a quantitative relationship existed at midseason between lesion density and fruit volume on nontreated fruit. Linear regressions were performed on data with lesion density as the independent variable and fruit volume as the dependent variable (REG procedure, SAS v. 8.0). Significance of the quantitative relationship was determined from the model's $F$ value. Aptness of a linear model was ascertained by examination of residual plots and graphs of predicted versus observed data. The third approach involved a comparison of fruit weight and volume across all fungicide treatments. Separate analyses of variance were performed on fruit volume and weight data collected at harvest in 1999 and 2000 (GLM procedure, SAS v. 8.0). Treatments were compared using the Waller-Duncan $k$-ratio $t$ test $(P \leq 0.05 ; k=$ 100).

Incidence-lesion density relationship. The quantitative relationship between lesion density and incidence was determined by fitting several models to the combined data set (1999 to 2001) using nonlinear regression analysis (NLIN procedure, SAS v. 8.0). Curvilinear functions fit to the data were the exponential model (EXP; $d=$ $\left.a \mathrm{e}^{\mathrm{bi}}\right)$, the exponential model with zero intercept $\left(\mathrm{EXP}_{0} ; d=a\left[\mathrm{e}^{\mathrm{bi}}-1\right]\right)$, the power function (POW; $d=a i^{\mathrm{b}}$ ), and the quadratic model with zero intercept (QUAD; $d=a i^{2}$ $+b i)$, where $i=$ disease incidence, $d=$ lesion density, and $a$ and $b$ are model parameters. The best model was determined by examining RVs of the parameter estimates and by graphical comparison of predicted and observed data points. The most appropriate model was used to generate separate regression functions for each year of the study. Full and reduced regression models were compared to determine if parameter estimates differed significantly across years.

\section{RESULTS}

Disease progression. In each year of the study, disease incidence and lesion density on nontreated fruit increased rapidly during the first 20 days of the epidemic, with onset occurring between days 134 and 138 (Fig. 1). The rate of the epidemic was slower in 2001, resulting in $40 \%$ fruit infection and 0.5 lesions/fruit by day 150 (Fig. 1E-F). In contrast, during the 1999 and 2000 epidemics, greater than $70 \%$ of the fruit were infected and 1.5 to 2.0 lesions/fruit were observed by day 150 (Fig. 1A-D). Consequently, disease incidence and lesion density in the first 2 years reached maximum values that were approximately 1.5 and 1.7 to 2.3 times higher, respectively, than observed in 2001. Following the progressive phase, disease levels remained fairly constant from days 170 to 210, which corresponded to the pit-hardening phase of fruit growth from mid-June through the end of July. A decline in incidence and lesion density was observed during the final 20- to 30-day period prior to harvest at the end of $\mathrm{Au}$ gust (Fig. 1A-D).

Management with fungicide. The application of fungicide dramatically reduced the intensity of the epidemics. As the number of fungicide applications $(\mathrm{N})$ increased, a concomitant decrease was observed in the amplitude of the disease progress curves (Fig. 1). This reduction in maximum disease level was most evident for the first four fungicide applications. Further decreases in disease incidence and lesion density amplitudes were not apparent as additional sprays were applied.

Based on plots of residuals and observed versus predicted values, the monomolecular model was most appropriate for the 1999 epidemic, whereas the logistic model was best for describing disease progression in 2000 and 2001. All regression models provided good to excellent fits to each treatment level as indicated by the significant $F$ values (Table 1) and examination of residual plots. In each year of the study, the estimated value of $r$ and $K_{\max }$ tended to decrease as the number of fungicide applications increased. Precision of these parameter estimates, as measured by their relative variation, was quite good; the majority of standard errors were less than $20 \%$ of the estimate (Table 1). In general, greater precision was obtained in estimating $K_{\max }$ than $r$, and in estimating 2000 and 2001 parameters versus those from 1999.

As indicated by the significant $F$ values $(P<0.05)$, the mathematical relationship between $\mathrm{N}$ and $\rho$ was adequately described by both the negative exponential and logistic decline functions (Table 2); the relationship between $\mathrm{N}$ and $K_{\max }$ was significant in five of the six year-model combinations (Table 3). However, examination of relative variation of each parameter estimate $\left(\mathrm{RV}_{\mathrm{M}}\right)$ showed that the logistic decline model had much greater precision in all but one case; in 1999, $\rho$ was best described as a function of $\mathrm{N}$ by the negative exponential model (Table 2). Plots of predicted and observed data verified the excellent fit of each regression model (Fig. 2).

Except for predicting $\rho$ in 1999 (Fig. $2 \mathrm{~A})$, the models depict an initial delay in the reduction of $\rho$ or $K_{\max }$ as the initial one or two fungicide sprays were applied, followed by a rapid decline in both parameter values (Fig. 2B-F). This decline occurred between two and four fungicide applications in 1999 and 2000 (Fig. 2B, D, and E); whereas, during the less intense epidemic of 2001, it was observed between one and three applications (Fig. 2C and F). In all cases, fungicide applied after the decline period failed to provide any apparent benefit in further reduction of either $\rho$ or $K_{\max }$. Based on visual examination of the modeled relationships between $\mathrm{N}$ and both epidemic parameters, the minimum number of fungicide applications needed to achieve adequate disease control was four, five, and three for 1999, 2000, and 2001, respectively.

All analyses of variance performed on AUDIC, AULDC, and final disease intensity for each year resulted in significant model and treatment $F$ values $(P<0.01)$. Mean comparison of AUDIC for both 1999 and 2000 showed a statistically significant decrease in disease level as fungicide applications increased from zero to four sprays (Fig. 3A and B). Additional applications beyond four did not result in further reduction of the AUDIC values. Analysis of AULDC for the 2000 season also resulted in a similar pattern (Fig. 3E). However, in 1999, the AULDC was reduced to a minimum after only three fungicide applications (Fig. 3D). In 2001, significant reductions in AUDIC or AULDC ceased after application of three sprays (Fig. 3C and F).

Disease intensity at harvest for most treatments was markedly lower than at the end of the progressive phase of the epidemic. For example, in 1999, maximum disease incidence levels of $0.87,0.73,0.59$, and 0.40 assessed in mid-June decreased to $0.51,0.41,0.43$, and 0.27 by August for zero, one, two, and three fungicide applica- 

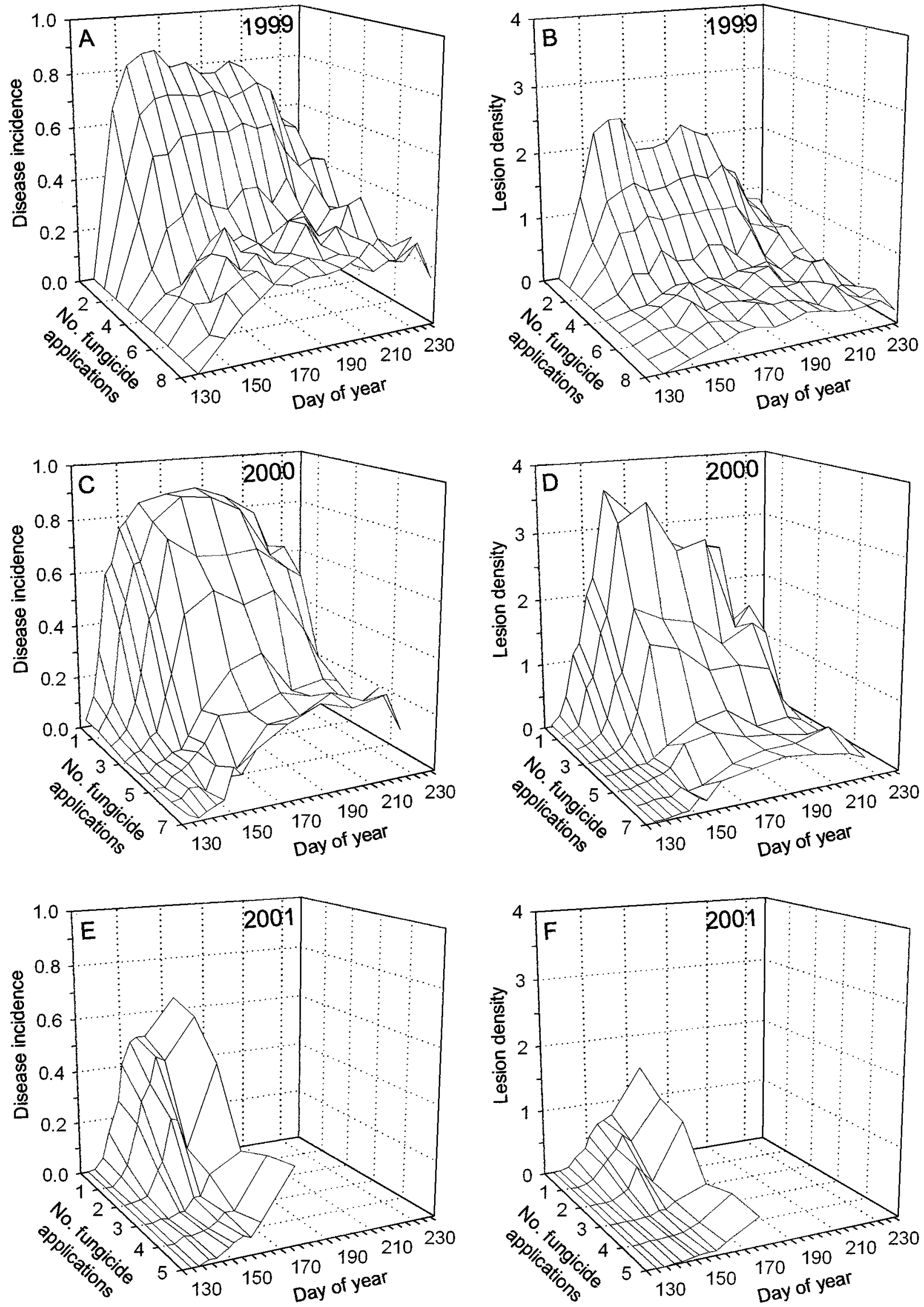

Fig. 1. Effect of the number of fungicide applications on the progression of rusty spot incidence (proportion infected fruit) and lesion density (number of lesions/fruit) during three growing seasons on 'Jerseyqueen' peach. Treatments consisted of different numbers of consecutive myclobutanil applications beginning at petal fall (>95\%) and continuing until midsummer. Each data point is the mean of five replicate trees sampled at 40 fruit/tree. 
tions, respectively. Similar reductions in disease incidence were observed in 2000 and in lesion density in both years. In general, the decrease was greater for fruit of those treatments that had higher initial levels of disease $(\mathrm{N}<4)$ than for those fruit that had lower levels as a result of better disease control $(\mathrm{N} \geq 4)$.

Given the differential reduction in disease incidence and lesion density that occurred at harvest, differences between treatments were less apparent. Consequently, fewer significant treatment differences were observed among final disease intensity means (Fig. 4) than among AU-
DIC and AULDC means (Fig. 3). Analysis of final disease intensity showed that one or two fungicide applications did not significantly reduce disease below that observed on the nontreated fruit (Fig. 4). A third application at first cover did result in significant disease control, but application of four or five applications, extending fungicide protection into July, did not further improve disease management.

Effect of disease on fruit growth. No significant differences in fruit volume $(P>$ $0.20)$ or weight $(P>0.29)$ were observed between healthy and diseased fruit. This outcome was evident at both midseason and at harvest in each year of the study (Fig. 5A). Furthermore, as the number of lesions per fruit increased on nontreated trees, the volume of the infected fruit remained constant (Fig. 5B). This observation was particularly evident in 1999 and 2001 , although, in 2000, fruit volume increased slightly as the number of lesions per fruit increased. However, none of the slopes of the linear regressions were significant, indicating the lack of a quantitative relationship between lesion density and fruit size. Examination of residual plots did not indicate that a curvilinear model was more appropriate.

Table 1. Fit of disease progression models to each fungicide treatment level and estimation of epidemic rate $(r)$ and maximum disease incidence $\left(K_{\max }\right)$ parameters for each growing season using nonlinear regression analysis ${ }^{z}$

\begin{tabular}{|c|c|c|c|c|c|c|}
\hline \multirow[b]{2}{*}{ No. fungicide applications } & \multirow[b]{2}{*}{ MSE } & \multirow[b]{2}{*}{$P>F$} & \multicolumn{2}{|c|}{ Rate } & \multicolumn{2}{|c|}{ Asymptote } \\
\hline & & & $r$ & $\mathbf{R V}$ & $K_{\max }$ & $\mathbf{R V}$ \\
\hline \multicolumn{7}{|l|}{ 1999, Monomolecular } \\
\hline 0 & 0.0017 & 0.0009 & 0.147 & 18.3 & 0.851 & 3.3 \\
\hline 1 & 0.0019 & 0.0016 & 0.087 & 20.9 & 0.767 & 6.3 \\
\hline 2 & 0.0025 & 0.0046 & 0.067 & 32.9 & 0.655 & 12.3 \\
\hline 3 & 0.0021 & 0.0132 & 0.046 & 59.7 & 0.467 & 7.3 \\
\hline 4 & 0.0009 & 0.0027 & 0.039 & 16.9 & 0.300 & 9.1 \\
\hline 5 & 0.0026 & 0.0376 & 0.054 & 78.5 & 0.336 & 34.9 \\
\hline 6 & $\ldots$ & $\ldots$ & $\ldots$ & $\ldots$ & $\ldots$ & $\ldots$ \\
\hline $\mathrm{RV}_{\mathrm{p}}$ & $\ldots$ & $\ldots$ & 37.9 & $\ldots$ & 14.7 & $\ldots$ \\
\hline \multicolumn{7}{|l|}{ 2000, Logistic } \\
\hline 0 & 0.0007 & $<0.0001$ & 0.279 & 7.5 & 0.857 & 1.7 \\
\hline 1 & 0.0024 & $<0.0001$ & 0.217 & 13.5 & 0.850 & 3.7 \\
\hline 2 & 0.0018 & $<0.0001$ & 0.258 & 14.7 & 0.704 & 3.9 \\
\hline 3 & 0.0007 & $<0.0001$ & 0.250 & 12.8 & 0.561 & 3.4 \\
\hline 4 & 0.0001 & $<0.0001$ & 0.138 & 7.7 & 0.384 & 3.0 \\
\hline 5 & 0.0003 & $<0.0001$ & 0.175 & 16.2 & 0.253 & 5.2 \\
\hline 6 & 0.0007 & $<0.0001$ & 0.089 & 32.4 & 0.271 & 20.9 \\
\hline $\mathrm{RV}_{\mathrm{p}}$ & $\ldots$ & $\ldots$ & 17.5 & $\ldots$ & 7.0 & $\ldots$ \\
\hline \multicolumn{7}{|l|}{ 2001, Logistic } \\
\hline 0 & 0.0015 & $<0.0001$ & 0.258 & 16.1 & 0.582 & 4.1 \\
\hline 1 & 0.0013 & $<0.0001$ & 0.215 & 16.0 & 0.572 & 6.0 \\
\hline 2 & 0.0049 & 0.0003 & 0.130 & 44.3 & 0.497 & 26.3 \\
\hline 3 & 0.0001 & $<0.0001$ & 0.215 & 13.6 & 0.241 & 5.1 \\
\hline 4 & 0.0003 & $<0.0001$ & 0.175 & 17.2 & 0.250 & 6.4 \\
\hline 5 & 0.0003 & $<0.0001$ & 0.162 & 17.0 & 0.275 & 5.6 \\
\hline 6 & $\ldots$ & $\ldots$ & $\ldots$ & $\ldots$ & & $\ldots$ \\
\hline $\mathrm{RV}_{\mathrm{p}}$ & $\ldots$ & $\ldots$ & 24.8 & $\ldots$ & 10.7 & $\ldots$ \\
\hline
\end{tabular}

${ }^{z}$ The total number of observations used in each analysis was 6 in 1999 and 10 in 2000 and 2001; all observations were means of the five experimental replicates. $\mathrm{RV}=$ percent relative variation $=($ standard error of parameter/parameter estimate $) \times 100$; all standard errors in nonlinear regression are approximated; $\mathrm{RV}_{\mathrm{p}}=$ mean parameter relative variation calculated across all available treatment levels. $\mathrm{MSE}=$ mean square for error.

Table 2. Results of nonlinear regression analysis when fitting the negative exponential and logistic decline models to weighted absolute infection rate ( $\rho$ ) as a function of number of fungicide applications

\begin{tabular}{|c|c|c|c|c|c|c|c|c|c|c|c|c|c|}
\hline \multirow[b]{2}{*}{ Year, model $^{x}$} & \multirow[b]{2}{*}{ MSE $^{y}$} & \multirow[b]{2}{*}{ Error df } & \multirow[b]{2}{*}{$F$ value } & \multirow[b]{2}{*}{$P>F$} & \multicolumn{4}{|c|}{ Parameter estimate } & \multicolumn{4}{|c|}{ Relative variation $^{w}$} & \multirow[b]{2}{*}{$\mathbf{R V}_{\mathbf{M}^{\mathbf{z}}}$} \\
\hline & & & & & $a$ & $b$ & $c$ & $d$ & $a$ & $b$ & $c$ & $d$ & \\
\hline \multicolumn{14}{|l|}{1999} \\
\hline Exponential & 7.01E-6 & 3 & 163.13 & 0.0009 & 0.0046 & 0.0579 & 0.6744 & & 63 & 6 & 16 & & 28 \\
\hline Logistic & $1.00 \mathrm{E}-5$ & 2 & 74.14 & 0.0133 & 0.0054 & 0.2873 & 0.7854 & -1.7781 & 98 & 495 & 80 & 505 & 294 \\
\hline \multicolumn{14}{|l|}{2000} \\
\hline Exponential & $1.50 \mathrm{E}-5$ & 4 & 36.53 & 0.0027 & -0.2101 & 0.2499 & 0.0272 & & 546 & 458 & 497 & $\ldots$ & 500 \\
\hline Logistic & $1.40 \mathrm{E}-5$ & 3 & 26.88 & 0.0114 & 0.0027 & 0.0354 & 1.126 & 3.0591 & 198 & 25 & 55 & 15 & 73 \\
\hline Exponential & 4.73E-6 & 3 & 28.85 & 0.0110 & 0.0044 & 0.0215 & 0.4766 & & 88 & 18 & 46 & $\ldots$ & 51 \\
\hline Logistic & $3.26 \mathrm{E}-7$ & 2 & 293.06 & 0.0034 & 0.0076 & 0.0180 & 2.3971 & 1.3744 & 5 & 5 & 14 & 6 & 8 \\
\hline
\end{tabular}

${ }^{\mathrm{w}}$ Relative variation $(\%)=$ (standard error of parameter/parameter estimate $) \times 100$; all standard errors in nonlinear regression are approximated.

${ }^{x}$ Negative exponential and logistic decline models described in text equations 2 and 3, respectively. The independent variable $\rho$ was estimated by first fitting the monomolecular (1999) or logistic (2000 and 2001) models to disease progress data for each level of the dependent variable, number of fungicide applications. The resulting rate parameters were standardized to $\rho$ by using text equation 1.

${ }^{\mathrm{y}} \mathrm{MSE}=$ mean square for error.

${ }^{\mathrm{z}} \mathrm{RV}_{\mathrm{M}}=$ mean relative variation calculated across all model parameters. 
The application of fungicide in each year of the study, regardless of the level of disease control, had no effect on fruit weight or volume based on the ANOVA $F$ values $(P>0.09)$. Although fruit size was significantly different for one pair of treatment means in 2000, no differences were observed among all other treatments (Fig. 5C).

Incidence-lesion density relationship. The relationship between disease incidence (i) and lesion density $(d)$ was most similar in 1999 and 2001 (Fig. 6). Although a majority of the data points from the 2000 season overlapped the other 2 years, approximately $12 \%$ of them had higher lesion density values for the same levels of incidence. This divergence in the 2000 data began at $i=0.2$, and increased as disease incidence approached unity.

The EXP, $\mathrm{EXP}_{0}$, and POW models provided better fits to the combined 19992001 data set than the QUAD model. The sums of the RVs for both parameter esti- mates in each model were 0.0449 (EXP), $0.0766\left(\mathrm{EXP}_{0}\right), 0.0286$ (POW), and 0.2188 (QUAD). Although the POW model had the lowest RV sum, both the POW and QUAD models underestimated lesion density at either disease incidence extreme $(0.4$ $>i>0.8$ ). In contrast, the EXP and $\mathrm{EXP}_{0}$ models had an equivalent scatter of observed data points above and below the predicted curves, providing the best overall fit.

Comparison of full and reduced $\mathrm{EXP}_{0}$ models for all 3 years of the study resulted

Table 3. Results of nonlinear regression analysis when fitting the negative exponential and logistic decline models to maximum disease incidence $\left(K_{\max }\right)$ as a function of number of fungicide applications

\begin{tabular}{|c|c|c|c|c|c|c|c|c|c|c|c|c|c|}
\hline \multirow[b]{2}{*}{ Year, model $^{x}$} & \multirow[b]{2}{*}{ MSE $^{y}$} & \multirow[b]{2}{*}{ Error df } & \multirow[b]{2}{*}{$F$ value } & \multirow[b]{2}{*}{$P>F$} & \multicolumn{4}{|c|}{ Parameter estimate } & \multicolumn{4}{|c|}{ Relative variation $^{w}$} & \multirow[b]{2}{*}{$\mathbf{R V}_{\mathbf{M}^{\mathrm{z}}}$} \\
\hline & & & & & $a$ & $b$ & $c$ & $d$ & $a$ & $b$ & $c$ & $d$ & \\
\hline \multicolumn{14}{|l|}{1999} \\
\hline Exponential & 0.0046 & 3 & 26.88 & 0.0122 & -0.7479 & 1.6268 & 0.0913 & & 360 & 164 & 206 & $\ldots$ & 243 \\
\hline Logistic & 0.0017 & 2 & 50.11 & 0.0196 & 0.2984 & 0.5526 & 1.5150 & 2.3678 & 16 & 15 & 38 & 11 & 20 \\
\hline \multicolumn{14}{|l|}{2000} \\
\hline Exponential & 0.0048 & 4 & 40.16 & 0.0022 & -5.1676 & 6.0784 & 0.0204 & $\ldots$ & 699 & 593 & 632 & $\ldots$ & 641 \\
\hline $\begin{array}{l}\text { Logistic } \\
2001\end{array}$ & 0.0009 & 3 & 146.79 & 0.0009 & 0.2353 & 0.6470 & 1.2220 & 2.9486 & 15 & 10 & 23 & 6 & 14 \\
\hline Exponential & 0.0082 & 3 & 673 & 0.0778 & -0.1116 & 0.7337 & 0.1559 & & 1.119 & 165 & 245 & . & 510 \\
\hline Logistic & 0.0008 & 2 & 54.45 & 0.0181 & 0.2619 & 0.3157 & 4.0001 & 2.2514 & 8 & 10 & 61 & 8 & 22 \\
\hline
\end{tabular}

${ }^{\mathrm{w}}$ Relative variation $(\%)=($ standard error of parameter/parameter estimate $) \times 100$; all standard errors in nonlinear regression are approximated.

x Negative exponential and logistic decline models described in text equations 2 and 3, respectively. The independent variable $K_{\max }$ was estimated by first fitting the monomolecular (1999) or logistic (2000 and 2001) models to disease progress data for each level of the dependent variable, number of fungicide applications. The resulting rate parameters were standardized to $\rho$ by using text equation 1 .

${ }^{\mathrm{y}} \mathrm{MSE}=$ mean square for error.

${ }^{\mathrm{z}} \mathrm{RV}_{\mathrm{M}}=$ mean relative variation calculated across all model parameters.
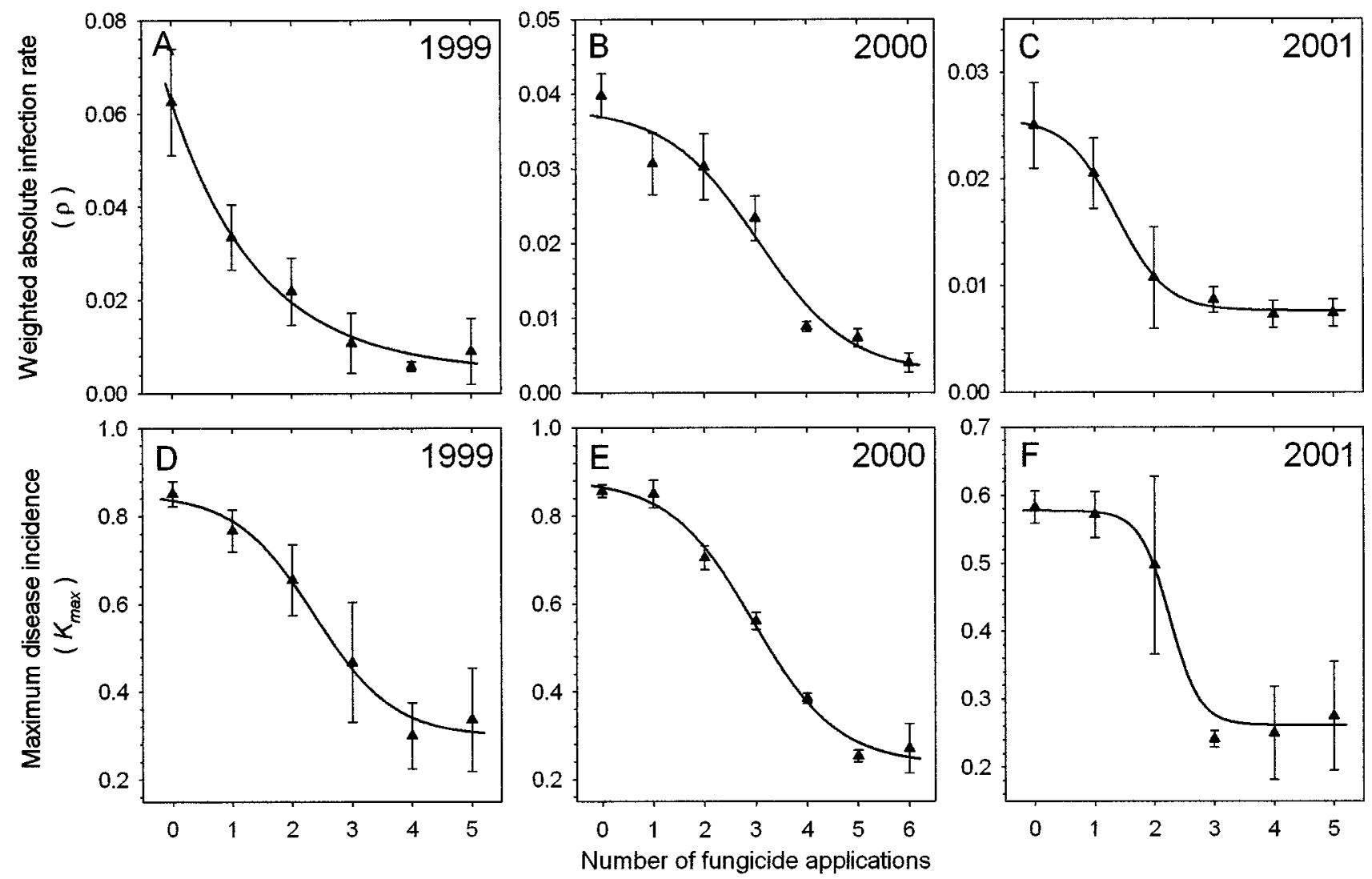

Fig. 2. Relationship between peach rusty spot epidemic parameters ( $\rho$ and $K_{\max }$ ) and the number of fungicide sprays applied to 'Jerseyqueen' peach during three growing seasons. Parameters were described as a function of the number of sprays by fitting either A, the negative exponential or B-F, logistic decline functions (Tables 2 and 3). Dependent variables (parameters) were generated by fitting the monomolecular (1999) or logistic (2000 and 2001) model to disease progression data (proportion infected fruit) for each fungicide treatment level (Table 1). Estimated infection rates $(r)$ were transformed to absolute rates $(\rho)$ via equation 1; bars represent standard error of the parameter estimates. 
in a highly significant $F$ value, indicating that one or both of the model parameters were not equal in at least 2 years (Table 4). When the function was fit separately for each year (full model), estimated values for the $a$ and $b$ parameters were 0.4039 and 2.1391 (1999), 0.2680 and 2.8863 (2000), and 0.4658 and 1.9520 (2001), respectively. These results showed that the 1999 and 2001 model parameter values were most similar, while the 2000 parameters were most different. Formal comparison of full and reduced models for each 2-year combination of data supported this conclusion (Table 4). One or both parameters from the 2000 model differed significantly from the 1999 and 2001 models. In contrast, the 1999 and 2001 model parameters were not significantly different. Consequently, data from 1999 and 2001 seasons were pooled and the resulting $\mathrm{EXP}_{0}$ model explained $95 \%$ of the variation in lesion density (Fig. 6). A separate model derived from the 2000 data, which described $88 \%$ of the variation, provided a better fit to the higher lesion density levels observed in that year.

\section{DISCUSSION}

The final fungicide application necessary for maximum control of peach rusty spot, based on analysis of epidemic pa- rameters, occurred between the first and third cover sprays. Given that applications began at $100 \%$ petal fall, these schedules resulted in a total of three to five fungicide applications per season, which are less than currently practiced by commercial New Jersey growers. For example, when fungicide sprays are initiated at shuck-split and continued on an 8- to 10-day schedule, orchards of mid- and late-season cultivars require six to eight applications, respectively. Thus, implementation of these results should yield a 17 to $63 \%$ reduction in fungicide usage without any loss in disease control, depending on seasonal variation, time of cultivar maturation, and current grower practices. Assuming a \$50/ha cost of application, these fungicide reductions translate into an economic savings of $\$ 50$ to $\$ 250 /$ ha.

The results of this study, which utilized fungicide applications to define the end point of the critical disease management period, mostly are in agreement with findings from previous reports which focused on the temporal relationship between disease progress and fruit development $(10,23)$. In these earlier works on rusty spot and powdery mildew of peach, disease intensity did not increase after initiation of pit-hardening, indicating that fruit were no longer susceptible. In the 1999 and 2000 results from our study, the final second and third cover applications occurred at 43 and 57 days after full bloom, respectively. This application timing agreed with observations of pit-hardening which, on cv. Jerseyqueen, began at approximately 50 days after full bloom. However, in 2001, the final first cover application occurred at only 27 days after full bloom, much earlier than would have been predicted based on phenology. We suspect this observed variation was due to environmental conditions that were less favorable for disease development; treatment infection rates in 2001 were about 30 to $60 \%$ lower than in the previous 2 years. Thus, further reduction in fungicide usage may be possible through implementation of a disease forecasting system based on environmental parameters.

The relationship between the number of successive fungicide applications $(\mathrm{N})$ made during an epidemic and the infection rate $(\rho)$ or maximum disease asymptote $\left(K_{\max }\right)$ has not been studied extensively. Most research has focused on the effect of fungicide concentration or application interval on disease progress $(5,6)$. In our 3-year study of peach rusty spot, the relationship between $\mathrm{N}$ and the epidemic parameters ( $\rho$ or $\left.K_{\max }\right)$ was best described by the logistic decline model. This model predicted a slow decrease in the infection rate or as-
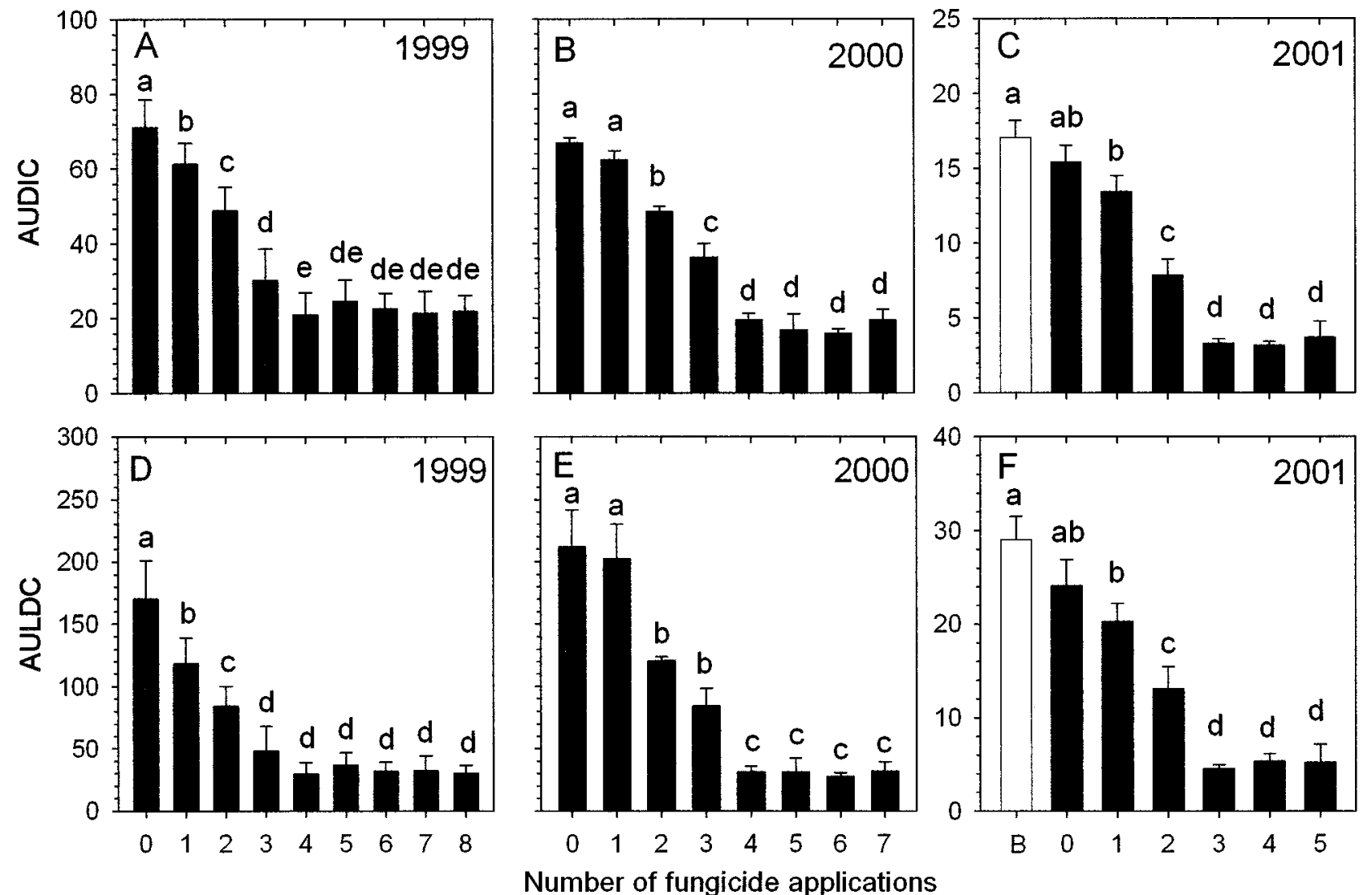

Fig. 3. Comparison of areas under rusty spot disease incidence (AUDIC) and lesion density (AULDC) curves calculated for each fungicide treatment level in each year of the study on 'Jerseyqueen' peach. Areas calculated for 1999 and 2000 used assessments made over the entire growing season; areas for 2001 were calculated using data gathered only during the progressive phase of the epidemic. Data are means of five replicate trees at 40 fruit/tree/assessment; vertical bars represent standard error of the means. Means assigned the same letter are not significantly different according to the Waller-Duncan $k$-ratio $t$ test $(P \leq 0.05 ; k=100)$. In 2001, a single fungicide application at full bloom was included in the study (labeled 'B'; open bars). 
ymptote parameter in response to fungicide applications at the beginning of an epidemic, followed by a rapid decline with additional applications, and ending with a diminished response. Our results agree with those from a potato late blight study that showed only a $17 \%$ reduction in the infection rate after one or two fungicide applications, but an $80 \%$ decrease after three to five applications (22). Although the decline in epidemic parameter values initially is slow, this fact does not necessarily diminish the importance of the early fungicide applications. In theory, the sub- sequent rapid decline phase may have resulted from the cumulative effect of all prior applications, not just those applied during the decline.

The goal of the model-based approach, used for determining the optimum timing of the final fungicide application, was to
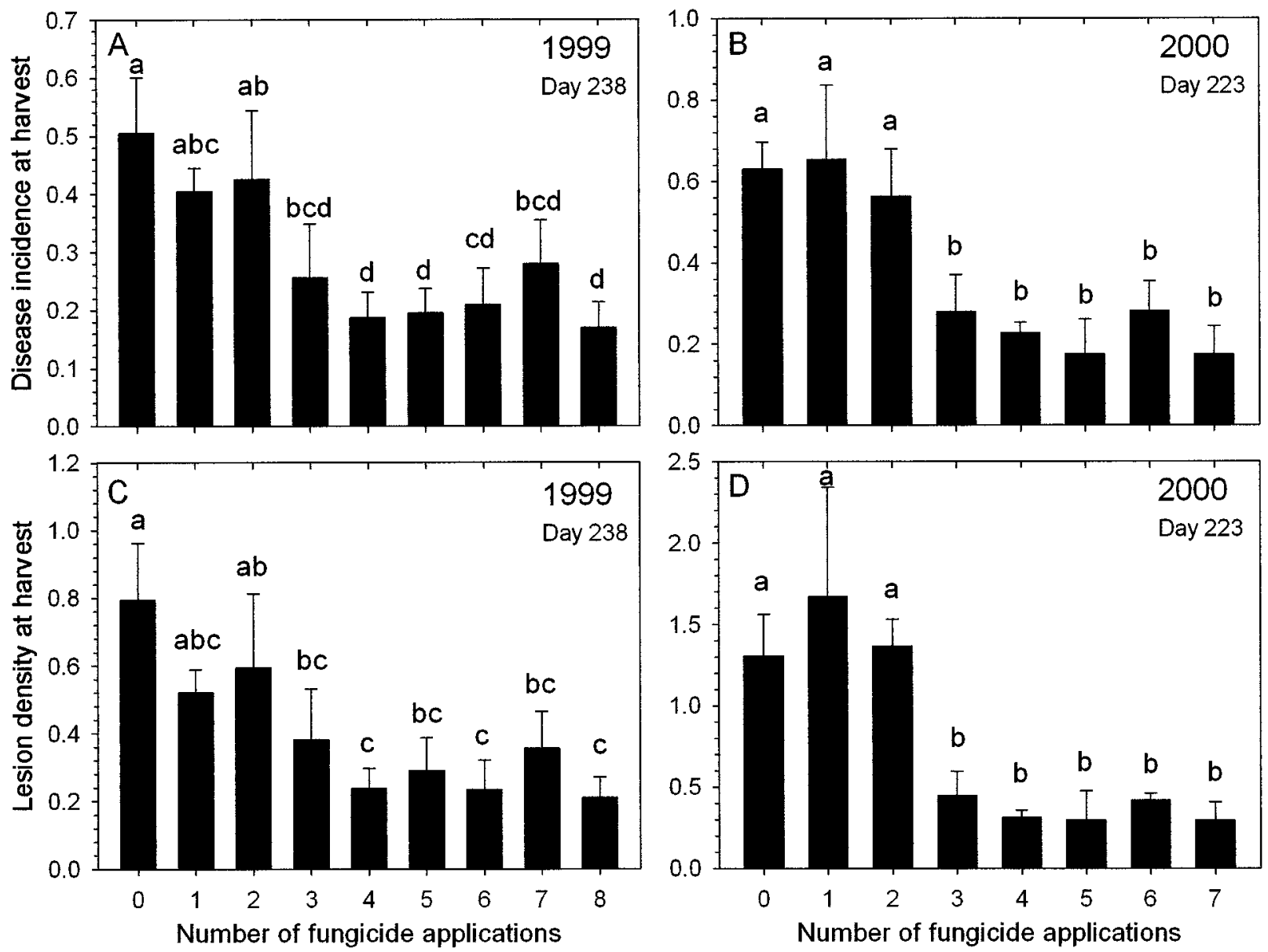

Fig. 4. Comparison of rusty spot disease incidence (proportion infected fruit) and lesion density (number of lesions/fruit) at harvest for each fungicide treatment level in 1999 and 2000 on 'Jerseyqueen' peach. Data are means of five replicate trees at 40 fruit/tree; vertical bars represent standard error of the means. Means assigned the same letter are not significantly different according to the Waller-Duncan $k$-ratio $t$ test $(P \leq 0.05 ; k=100)$.
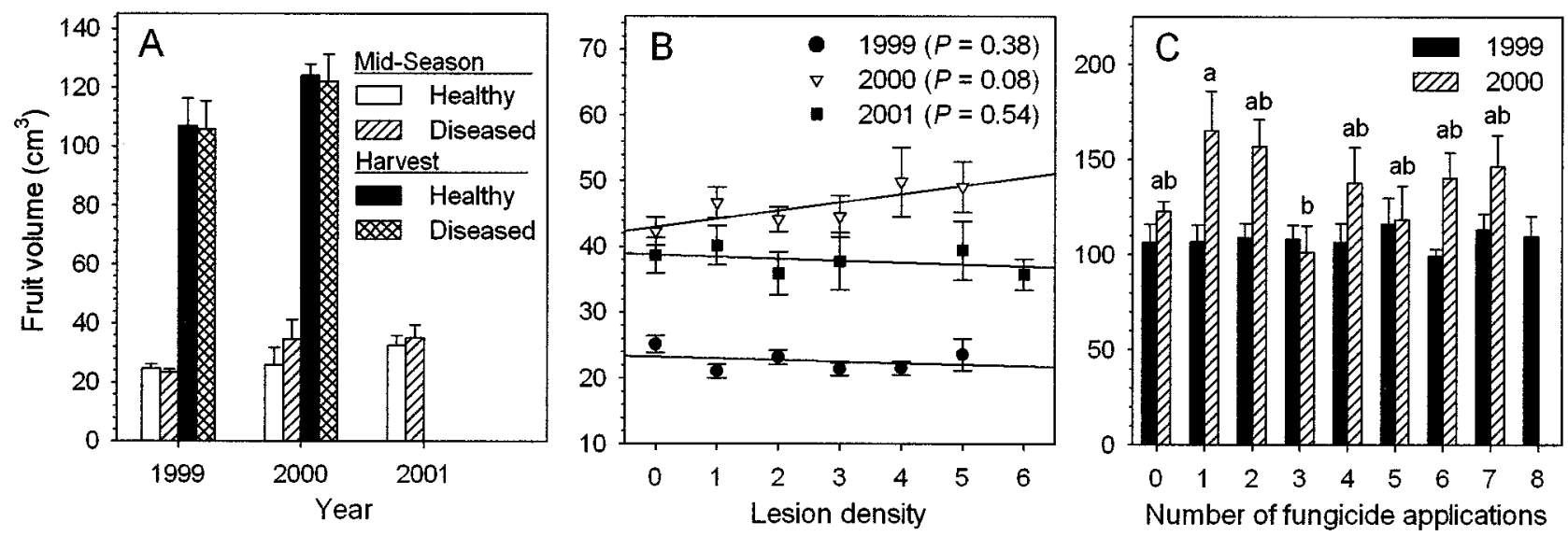

Fig. 5. Effect of peach rusty spot on 'Jerseyqueen' fruit size during the 1999, 2000, and 2001 growing seasons. A, Comparison of healthy and diseased fruit at midseason (days 168-173) and at harvest (days 223-238) on nonsprayed trees. No significant differences were observed at either time in any year. B, Relationship between lesion density (number of lesions per fruit) and fruit volume at midseason on nonsprayed trees. $P$ values indicate significance of the slopes of straight lines fit to the data. C, Comparison of fruit volumes at harvest (days 223-238) for treatments consisting of different numbers of fungicide applications. For 2000 results, means assigned the same letter are not significantly different according to the Waller-Duncan $k$-ratio $t$ test $(P \leq$ $0.05 ; k=100)$; no significant differences were observed among 1999 means. Vertical bars in all graphs indicate standard error of the mean. 
minimize the infection rate and asymptote parameters of the disease progress models. These models described only the progressive phase of the epidemic; therefore, this approach assumed that disease intensity could be reduced only during this phase. However, rusty spot epidemics display a degressive (disease decline) phase just prior to harvest, many weeks after termination of the progressive phase (10). Analyses of AUDIC, AULDC, and final disease intensity at harvest indicated that this decline alters the treatment effects, allowing for further refinement of fungicide timing. Results of the AUDIC and AULDC data analyses showed that three to four applications provided effective disease management, while analysis of final disease intensity indicated that only three applications were needed. Second and third cover applications appear unnecessary for disease management. However, before this refinement can be adopted commercially, further research is needed on the cause of the decline and confirmation of its occurrence on other cultivars.

Current recommendations stipulate that the first fungicide application should be applied at the shuck-split stage of fruit development (11). However, in immature fruit that are not yet large enough to split open the calyx, the fruit surface still is exposed to the environment. The perigynous peach flower has a superior ovary that is surrounded by but not fused to the floral tube $(4,25)$; an opening exists at the top of the floral tube through which spores could gain entry. Thus, in our study, the first fungicide application was applied one phenological stage earlier, at petal fall. In 1999, the AUDIC and AULDC were reduced significantly when a single application was made at petal fall, thereby indicating that infection may be occurring at this very early stage; however, no significant reductions were observed in 2000 and 2001. Thus, the amount of infection that occurs at this stage may be relatively small, variable, and dependent on occurrence of other factors such as favorable environmental conditions. Comparison of a fungicide program beginning at petal fall with one initiated at shuck-split should help to elucidate the importance of control at this early stage. A single application of fungicide in 2001 at the next earliest stage, full bloom, did not significantly reduce disease intensity below that on nonsprayed trees; additional data are needed to confirm this result.

Although application of myclobutanil during the progressive phase substantially reduced disease incidence and density of rusty spot lesions, we did not observe a high level of disease control. In 1999, 2000 , and 2001, control at midseason was 71,76 , and $61 \%$, respectively, for those treatments consisting of at least four applications. Regardless of the number of fungicide applications, disease incidence at midseason was never less than 20 to $25 \%$. Infection occurred even though application intervals were shorter during the critical exponential phase of disease increase between petal fall and second cover (10). In contrast, application of myclobutanil at the same rate and phenological timing on 'Jerseyglo' peach in 2000 and 2001 resulted in 93 and $91 \%$ disease control, respectively (9). However, maximum incidence of rusty spot on nonsprayed Jerseyglo fruit was only 36 to $49 \%$ of that observed on Jerseyqueen fruit. Therefore, the lack of adequate control on Jerseyqueen may have been due to a higher degree of susceptibility, which in turn augmented the infection rates. Periodic applications of fungicides have been shown to be less effective at controlling epidemics when the infection rate on un- protected plants is high than when it is moderate (17). Further research is needed to confirm the existence and determine the levels of susceptibility among cultivars and the degree of its impact on epidemics. Integration of plant disease resistance with fungicide control should lead to further improvement of rusty spot management.

Peach rusty spot had no effect on growth of the fruit. Although the density of lesions on nontreated fruit was as much as four times greater than on fungicide-treated fruit, no significant difference in fruit volume or weight was observed among the various treatment levels. Furthermore, on nontreated fruit, increasing lesion density from zero to six lesions per fruit did not affect fruit volume. This lack of response was evident whether fruit were assessed

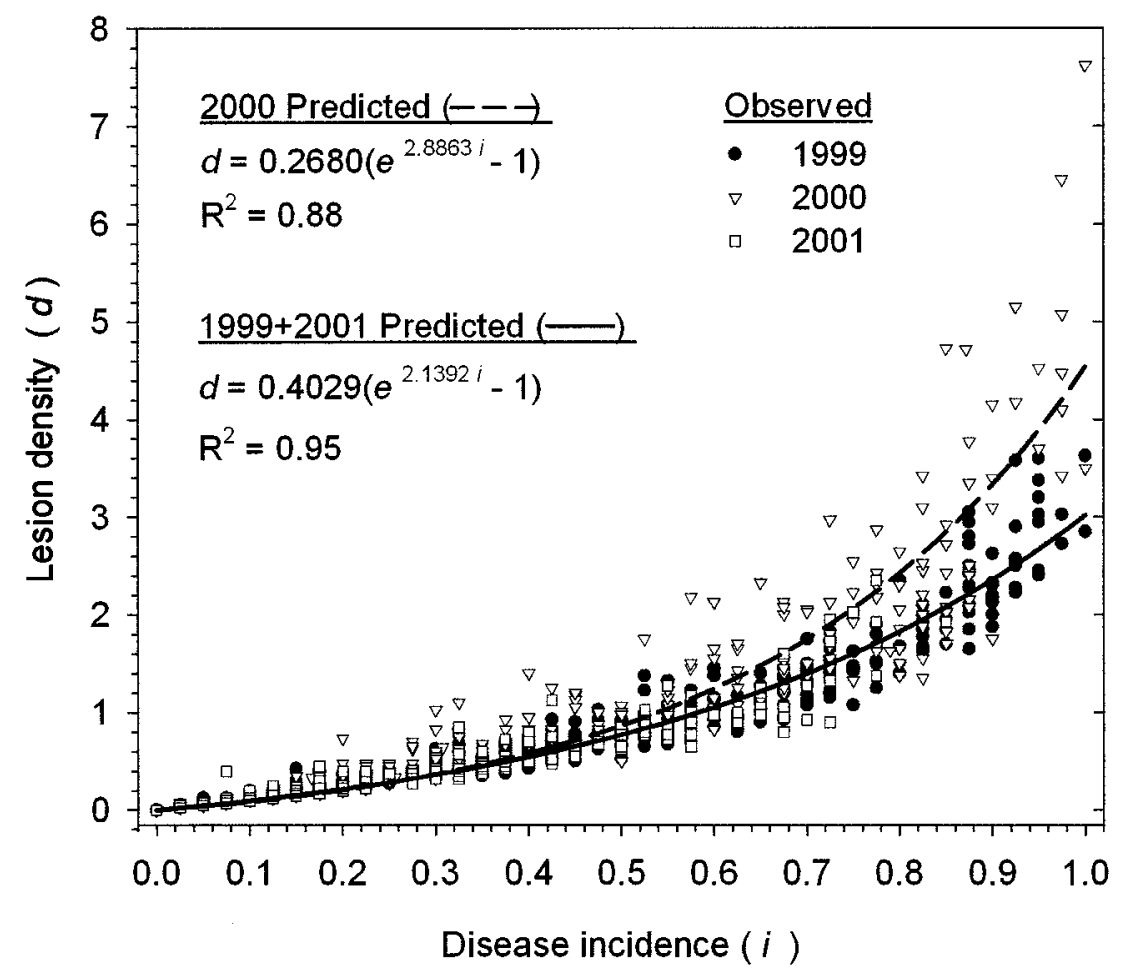

Fig. 6. Relationship between peach rusty spot disease incidence (proportion infected fruit) and lesion density (number of lesions per fruit) on 'Jerseyqueen' fruit during three growing seasons. Each data point represents the mean of 40 fruit/tree. Curves represent predicted values of the exponential model fit to the data via nonlinear regression analysis. Coefficients of determination were calculated as $R^{2}=1-\left(\mathrm{SSE} / \mathrm{SST}_{\text {corrected }}\right)$. Parameters of the 1999 and 2001 models were not significantly different, allowing data to be pooled (Table 4).

Table 4. Comparison of full versus reduced disease incidence-lesion density regression models when fitting the exponential function to the 3-year data set and all 2-year combinations of data

\begin{tabular}{lcccc}
\hline & \multicolumn{4}{c}{ Sum of squares of error } \\
\cline { 2 - 5 } Model comparison $^{\mathbf{y}}$ & Full model & Reduced model & $\boldsymbol{F}$ value $^{\mathbf{z}}$ & \multicolumn{1}{c}{$\boldsymbol{P}>\boldsymbol{F}$} \\
\hline 1999 vs. 2000 vs. 2001 & 82.93 & 111.30 & 131.04 & $<0.0001$ \\
1999 vs. 2000 & 78.88 & 106.30 & 204.96 & $<0.0001$ \\
1999 vs. 2001 & 19.31 & 19.37 & 1.32 & 0.2665 \\
2000 vs. 2001 & 67.66 & 71.51 & 24.92 & $<0.0001$ \\
\hline
\end{tabular}

y The zero-intercept version of the exponential function, $d=a\left(\mathrm{e}^{\mathrm{bi}}-1\right)$, was used to fit all full and reduced models where $d=$ lesion density, $i=$ disease incidence, and $a$ and $b$ are parameters. Numbers of observations used in the analyses were 658, 525, and 355 for the 1999, 2000, and 2001 data sets, respectively.

${ }^{\mathrm{z}}$ Alternative conclusions for the $F$ test are $\mathrm{C}_{1}$ : all model parameters equal or $\mathrm{C}_{2}$ : either one or both parameters not equal; probabilities for $F$ values calculated by the PROBF function (SAS v. 8.0). 
midseason after growth stage I, the period of cell division, or at harvest after growth stage III, the period of cell enlargement (24).

In contrast to our results, an earlier study conducted on 'Rio Oso Gem' peach reported that the weights of diseased fruit were significantly lower (5.5 to $9.7 \%$ ) than healthy fruit during midseason (18). This discrepancy in midseason results may be due to a difference in cultivar susceptibility. However, in our study, mean lesion density on Jerseyqueen was almost five times greater than was reported on Rio Oso Gem. Thus, one possible explanation may be that Jerseyqueen is more tolerant to infection. Another possible reason may be that the earlier study represents an anomaly, because only 1 year of data was presented versus 3 years in our study. Nevertheless, regardless of the midseason results, we observed at harvest that healthy fruit were not significantly larger or heavier than diseased fruit.

The mathematical relationship between disease incidence and lesion density (a measure of severity) was best described by the no-intercept version of the exponential model $\left(\mathrm{EXP}_{0}\right)$. Unlike the exponential model (EXP), $\mathrm{EXP}_{0}$ was considered the more appropriate because it complies with the biological requirement of predicting zero lesion density when disease incidence is zero. The data and derived regression function depicted a rather slow initial increase in lesion density with increasing incidence. On average, lesion density did not exceed 1 lesion/fruit until after 54 to $58 \%$ of the fruit became infected. Although this model provided an excellent fit to the data in each year, statistical comparisons indicated that the estimated parameters were similar in only 2 of the 3 years. Such seasonal variability in incidence-severity relationships is not uncommon in plant pathosystems; similar results have been reported for apple powdery mildew (20), wheat powdery mildew (12), and wheat leaf rust (12). The disparity in models among years for peach rusty spot was greatest at high incidence levels. Between $i$ $=0$ and $i=0.5$, the relationship was near linear and much more similar for each of the study years. Thus, prediction of lesion density within this incidence range, which would be the expected range for commercial orchards, should be possible with a reasonable degree of precision. Data from additional years is needed to test the applicability of this approach.

Myclobutanil has been shown to be much more effective at controlling peach rusty spot than sulfur, a fungicide com- monly used for control of powdery mildews (13). Hence, myclobutanil was chosen for use in our study on the highly susceptible Jerseyqueen peach. This fungicide was used exclusively so that treatments differed only in the number and timing of applications. Ideally, commercial application of our findings would integrate fungicides with different modes of action so as to minimize development of pathogen resistance. However, the pathogen does not sporulate readily on peach $(1,2,11,21)$, and all inoculum is believed to originate from outside the peach orchard $(10,14,19)$; therefore, the importance of mixing or alternating fungicides as a resistance management strategy remains to be determined.

A recent temporal analysis of peach rusty spot epidemics revealed that disease increased in a logistic fashion from the shuck-split stage of fruit development until 60 days after full bloom (10). Thus, our study did not include fungicide treatments that began at later timings, such as at first cover. Delaying application of fungicide would have ignored the rapid exponential increase in disease that occurs during these early stages of fruit growth. Indeed, we chose to examine even earlier application timing, beginning at petal fall, in an attempt to better manage disease development. However, further reduction in fungicide usage still may be possible by increasing the time interval between fungicide applications, thereby reducing the total number of applications. Although this approach may require an increase in fungicide concentration for each application, the overall net result may be a decrease in total amount of fungicide applied per season.

\section{ACKNOWLEDGMENTS}

We thank K. A. Foster and V. L. Roberts for their technical assistance.

\section{LITERATURE CITED}

1. Blodgett, E. C. 1941. Rusty spot of peach. Plant Dis. Rep. 25:27-28.

2. Blodgett, E. C. 1941. Fruit diseases in Idaho. Plant Dis. Rep. 25:233-235.

3. Campbell, C. L., and Madden, L. V. 1990. Introduction to Plant Disease Epidemiology. John Wiley \& Sons, New York.

4. Esau, K. 1977. Anatomy of Seed Plants. John Wiley and Sons, Inc., New York.

5. Fry, W. E. 1975. Integrated effects of polygenic resistance and a protective fungicide on development of potato late blight. Phytopathology 65:908-911.

6. Fry, W. E. 1977. Management with chemicals. Pages 213-238 in: Plant Disease, An Advanced Treatise, Vol. I. How Disease is Managed. J. G. Horsfall and E. B. Cowling, eds. Academic Press, New York.

7. Fry, W. E. 1982. Principles of Plant Disease
Management. Academic Press, Inc., Orlando, FL.

8. Furman, L. A., Lalancette, N., and White, J. F. 2000. Quantitative epidemiology of peach rusty spot: Disease progress and management. (Abstr.) Phytopathology 90:S26.

9. Furman, L. A., Lalancette, N., and White, J. F. 2001. Peach rusty spot biological/biorational disease management. (Abstr.) Phytopathology 91:S30.

10. Furman, L. A., Lalancette, N., and White, J. F. 2003. Peach rusty spot epidemics: temporal analysis and relationship to fruit growth. Plant Dis. 87:366-374.

11. Grove, G. G. 1995. Rusty spot. Page 15 in: Compendium of Stone Fruit Diseases. J. M Ogawa, E. I. Zehr, G. W. Bird, D. F. Ritchie, K. Uriu, and J. K. Uyemoto, eds. The American Phytopathological Society Press, St. Paul, MN.

12. James, W. C., and Shih, C. S. 1973. Relationship between incidence and severity of powdery mildew and leaf rust on winter wheat. Phytopathology 63:183-187.

13. Lalancette, N., and Robison, D. 1999. Comparison of fungicides for control of rusty spot and brown rot on peach, 1998. Fungic. Nematicide Tests 54:60.

14. Manji, B. T. 1972. Apple mildew on peach (Abstr.) Phytopathology 62:776.

15. Neher, D. A., and Campbell, C. L. 1992. Underestimation of disease progress rates with the logistic, monomolecular, and Gompertz models when maximum disease intensity is less than 100 percent. Phytopathology 82:811-814.

16. Polk, D., Schmitt, D., Rizio, E., and Peterson, K. 1998. The economic impact of peach pests in New Jersey 1996-1997. N. J. State Hortic. Soc. Hortic. News 78(1):3-10.

17. Rowell, J. B. 1972. Fungicidal management of pathogen populations. J. Environ. Qual. 1:216-220.

18. Ries, S. M., and Royse, D. J. 1977. Rusty spot of peach in Illinois. Plant Dis. Rep. 61:317318.

19. Ries, S. M., and Royce, D. J. 1978. Peach rusty spot epidemiology: Incidence as affected by distance from a powdery mildew infected apple orchard. Phytopathology 68:896899.

20. Seem, R. C., and Gilpatrick, J. D. 1980. Incidence and severity relationships of secondary infections of powdery mildew of apple. Phytopathology 70:851-854.

21. Sprague, R., and Figaro, P. 1956. Rusty spot, powdery mildew and healthy skin of peach fruits compared histologically. (Abstr.) Phytopathology 46:640.

22. van der Plank, J. E. 1963. Plant Diseases: Epidemics and Control. Academic Press, Inc., New York.

23. Weinhold, A. R. 1961. The orchard development of peach powdery mildew. Phytopathology $51: 478-481$.

24. Westwood, M. N. 1993. Temperate-Zone Pomology: Physiology and Culture. Timber Press, Inc., Portland, OR.

25. Wilson, C. L., Loomis, W. E., and Steeves, T. A. 1971. Botany. Holt, Rinehart, and Winston, Inc., New York.

26. Zadoks, J. C., and Schein, R. D. 1979. Epidemiology and Plant Disease Management. Oxford University Press, New York. 